\title{
EDITORIAL
}

\section{Maternal health Indicators Signal Optimism}

\section{Abraham Haileamlak, MD, Professor of Pediatrics and Child Health}

Maternal health is a major health priority for international agencies and the Ethiopian Government. Many low income countries including Ethiopia, made substantial improvements in maternal health achieving the Millennium Development Goal -5. According to World Health Organization estimation, maternal death decreased almost by half in the last 15 years globally (2).

The last five demographic health surveys in Ethiopia showed improving trends of most of process indicators of maternal health services including reduction of maternal death has been improved over time. Though the contraceptive prevalence rate showed significant improvement, the unmet need of family planning has increased which may be explained by better awareness of clients in contrary to the poor service coverage (2-5).

After the end of MDGs era, experts in the world under the leadership of United Nation, set a post Millennium Development Goal (SDG) agenda called Sustainable Development Goals which will be implemented until 2030. The SDG has seventeen goals and 169 targets as a whole where SDG 3 deals with ensuring health lives and promote wellbeing for all at all ages. SDG 3 has nine targets and four sub targets related with different areas of health. The first target under SDG 3 is to achieve a reduction of global maternal mortality ratio to less than 70 per 100,000 live births (6).

By owning the SDG agenda, the Ethiopian 20 year Visioning document targets to reduce MMR to $267 / 10^{5}$ live births(LBs), $101.4 / 10^{5} \mathrm{LBs}$ and $45.5 / 10^{5} \mathrm{LBs}$ by; increase antenatal care coverage to $86 \%, 77 \%$ and $87 \%$; increase skilled birth attendance to $62 \%, 77 \%$, $95.1 \%$ by 2015,2025 and 2035 , respectively (MOH website). To achieve this them $\mathrm{MOH}$ plans to improve Emergency obstetric care, Quality maternal and newborn health care, Emergency obstetrics referral network, maternal death surveillance and response, Safe abortion service and Youth \& adolescent RH (YARH) among others (7).

The current issue (Vol. 27, No 2), the second regular issue for the year, contains one editorial, seven original articles, two reviews and four case reports. The editorial, three of the original articles and one of the reviews are focusing on maternal health. The other articles and case reports covered various topics.

I invite readers to go through these articles and appreciate or utilize the contents. I also encourage readers to forward comments and suggestions to the editor or corresponding authors.

\section{REFERENCES}

1. WHO. Maternal Mortality. http://www.who.int/mediacentre/factsheets/fs 348/en/ (accessed 27 Feb. 2917).

2. UNFPA. "Trends in maternal Health in Ethiopia" (PDF). UNFPA. (accessed on 28, Feb. 2017).

3. Central Statistics Agency. Demographic and Health Survey 2005Ethiopia.

4. Central Statistics Agency. Demographic Health Survey 2011 Ethiopia.

5. Central Statistics Agency. Demographic Health Survey 2016 Ethiopia.

6. United Nations. Sustainable Development Goals.

http://www.un.org/sustainabledevelopment/s ustainable-development-goals/ (accessed on 28, Feb. 2017).

7. MOH. Visioning Ethiopia's Path Towards Universal Health Coverage Through Primary Health Care. Addis Ababa, 2014. 